\title{
Editorial: Advances in Neonatology
}

\author{
Dharmapuri Vidyasagar
}

Received: 3 April 2014 / Accepted: 7 April 2014 / Published online: 17 April 2014

(C) Dr. K C Chaudhuri Foundation 2014

It is with pleasure I like to introduce the readers of this journal to the forthcoming series of articles under the title of "Advance in Neonatology". The mission of this journal always has been to keep the readers abreast of scientific advances and translation of medical research in pediatrics into practice guidelines. The specialty of Neonatology is a fast advancing specialty. In trying to keep up with advances we always seek papers from experts in the field from around the globe.

Dr. Verma, the Chief Editor has been kind to invite me to take the lead of formulating the theme of the issues on "Advances in Neonatology".

I have in my earnest pursuit identified topics of interest to practitioners and reached out to experts in the respective special fields of Neonatology. It has not been an easy task, for the topics of interest are many and advances likewise are numerous. We have chosen topics of practical importance and the authors of repute in their field. In spite of constraints of time the authors have given their precious time to this project so that readers will be benefited with the most current information.

In this issue we publish first four of the series. These articles deal with the current recommendations of antenatal and postnatal steroids, a topic of great interest to both obstetricians and neonatologists. Bartholomew and Papageorgiou with their vast experience over the last three

\footnotetext{
D. Vidyasagar $(\bowtie)$

Department of Pediatrics, University of Illinois at Chicago, Chicago, IL, USA

e-mail:dvsagarmd@yahoo.com

D. Vidyasagar

Sri Ramchandra Medical College, Chennai, Tamil Nadu, India

D. Vidyasagar

Center for Global Health, University of Illinois at Chicago, Chicago, IL, USA
}

decades provide valuable guidelines for antenatal use of steroids in mothers at risk of delivering premature babies. They also discuss the use of postnatal steroids in infants with the potential of developing chronic lung disease, a subject of great interest in the neonatal circles [1].

Kumar and colleagues, experts in training neonatal resuscitation program (NRP), deal with history of NRP and most importantly tell us how the recommendations of every step of intervention in NRP are based on evidence not on opinions. They also show that the guidelines of NRP, which are almost used universally, are the work of multinational experts. Also the development of NRP is "Work in Progress", meaning they are constantly subject to change based on "new evidence" [2]. Here the readers have the opportunity to identify "gaps in knowledge" of NRP and design studies to explore for the new answers.

Murki and colleagues discuss the use of CPAP and surfactant in the treatment of respiratory distress syndrome (RDS). They present the evidence that early CPAP in level II NICU and in developing, resource poor countries may be a better first choice to using surfactant therapy [3].

Kasivajjula and Maheshwari review the pathophysiology and treatment options for managing necrotizing enterocolitis (NEC), a continuing problem in the NICU all over the world [4].

We hope the readers will find the information contained in this issue and subsequent issues very useful.

I thank the authors and the editorial staff for their help in making the project possible.

\section{References}

1. Bartholomew J, Kovacs L, Papageorgiou A. Review of the antenatal and postnatal use of steroids. Indian J Pediatr. 2014. doi:10.1007/ s12098-014-1376-9. 
2. Kumar P, Yamada NK, Fuerch JH, Halamek LP. The neonatal resuscitation program: current recommendations and a look at the future. Indian J Pediatr. 2014. doi:10.1007/s12098-013-1332-0.

3. Murki S, Deorari A, Vidyasagar D. Use of CPAP and surfactant therapy in newborns with respiratory distress syndrome. Indian J Pediatr. 2014. doi:10.1007/s12098-0141405-8.

4. Kasivajjula H, Maheshwari A. Pathophysiology and current management of necrotizing enterocolitis. Indian J Pediatr. 2014. doi:10.1007/ s12098-014-1388-5. 